\title{
Tutors and Learners Without Borders: In a Relationship but it's Complicated
}

\author{
Juvy Lizette Gervacio (juvylizette.gervacio@upou.edu.ph) \\ University of the Philippines Open University
}

\begin{abstract}
Global tutoring and learning communities are composed of different people who share a common interest or a common goal. Learners aim to acquire knowledge and skills; while tutors aim to provide content support, coaching and motivation to learners. The interaction is done through the use of technology, specifically the Internet. Management of these communities can be a challenge because members are not only separated by space and time but they come from different cultures, contextual backgrounds and institutions. If managed well, global tutoring and learning communities can transcend barriers and be very effective, efficient and also inexpensive.

The paper looks into how online tutors and learners are effectively and efficiently managed and sustained. Specifically, it aims to: a) define global tutoring and learning communities and their rationale; b) describe the strategies and good practices employed in the planning, implementation, monitoring and evaluation; c)determine the effective communication tools used to manage and sustain global teams; and d) identify the challenges and lessons to maintain and sustain global tutoring and learning communities.

The paper is based on studies as well as actual experiences and written reports on managing global learning and tutoring communities. It will look into how teams are managed from planning, implementation to monitoring and evaluation. Specifically, it will provide a glimpse on how learners and tutors from different countries and nationalities are managed in the elearning Development and Implementation (eLDI) program and e-skills program. These courses are jointly offered by the University of the Philippines Open University (UPOU) and InWEnt, Capacity Building International, Germany and have learners and tutors from various countries not only from Asia, but from Africa and the Middle East. The paper also draws lessons on how to maintain tutors and learners without borders.
\end{abstract}




\section{Introduction}

Global tutoring and learning communities comprise of different people who share a common interest or a common goal. Learners aim to acquire knowledge and skills; while tutors aim to provide content support, coaching and motivation to learners. Interaction is through the use of technology, specifically the Internet. Managing these communities can be a challenge because members are not only separated by space and time but they also come from different cultural, language and contextual backgrounds and institutions, and speak a variety of languages. If managed well, global tutoring and learning communities can transcend barriers and be very effective, efficient and inexpensive.

In project management, it is important to consider the different activities from project planning, implementation, monitoring and evaluation. In each phase of project management, there are some factors that need to be considered in order to ensure success and achieve its goals.

\section{Objectives}

The paper looks into how online tutors and learners are effectively and efficiently managed and sustained. Specifically, it aims to: a) define global tutoring and learning communities and their rationale; b) describe the strategies and good practices employed in the planning, implementation, monitoring and evaluation; c) determine the effective communication tools used to manage and sustain global teams; and d) identify the challenges and lessons in maintaining and sustaining global tutoring and learning communities.

\section{Framework of the Study}

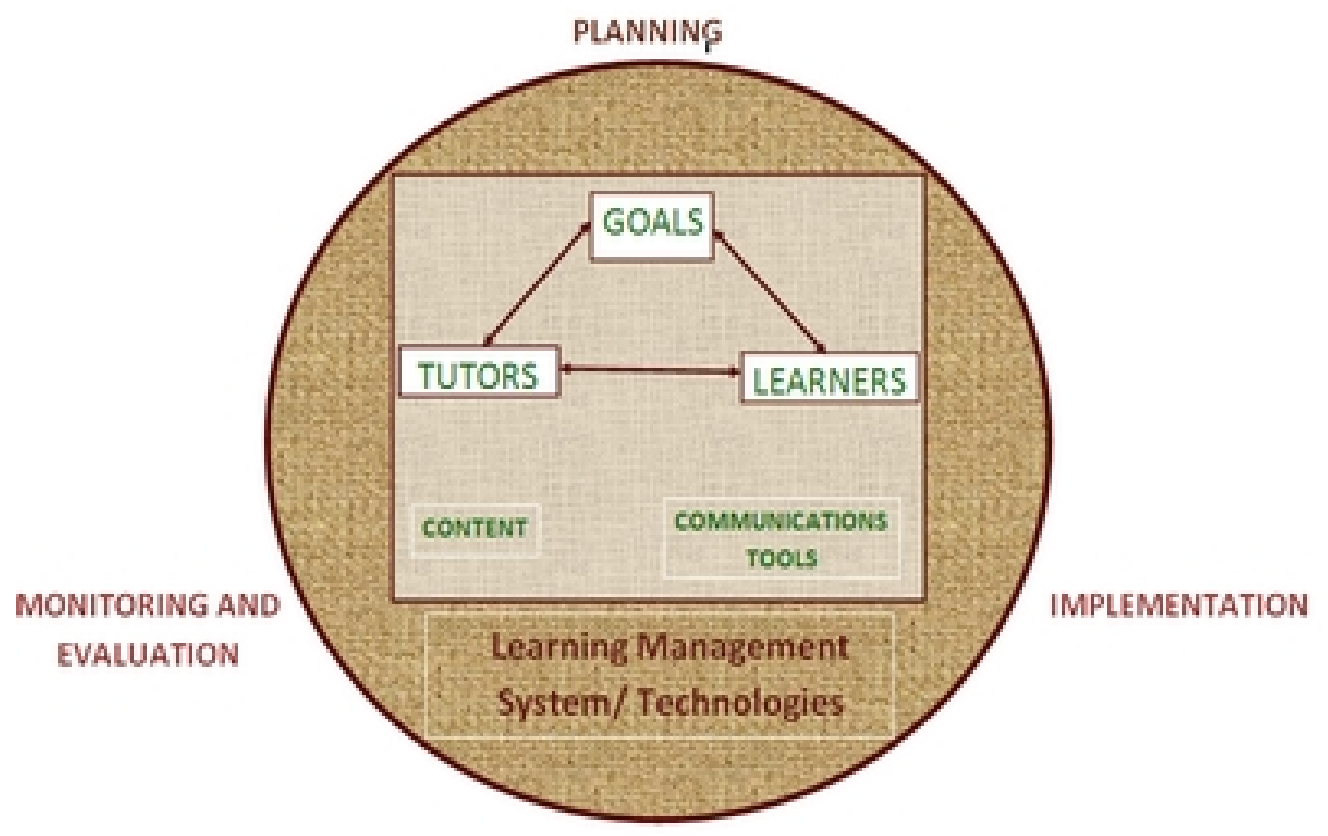

Figure 1: Framework of the Study 
For this paper, four factors that would contribute to the success in managing global learning communities were identified, namely clear goals, relevant content, effective communications tools and easy-to-use learning management systems/technologies.

Clear Goals. In Project Planning, the goals should be clearly defined and communicated to everyone from the beginning. It is important to know who the members of the project team are, who has to do what and when. It is also important to draw up a financial plan which includes how the project will be financed. The cost for each activity is calculated.

Tutoring and Learning Communities. The members of the tutoring community are determined based on their qualifications such as knowledge, familiarity with eLearning and good communications skills. It is important that tutors have excellent written communication skills since they interact with people coming from different cultures and language backgrounds.

The target participants or members of the learning community are expected to have some basic knowledge and skills in technology so that they can participate actively in the course.

Content. The contents are identified during the planning of the project. What are the contents of the project? How will the tutoring and learning communities be informed of the content? Handbooks for tutors and learners are very important. The handbooks will provide them with guidance on the content, schedule, requirements, activities, tasks and the contacts.

Learning Management System/Technology. Technologies used are crucial in managing global learning communities, and these include the learning management system. Every member of the virtual community should have quality access to technology because technological access can hamper the success of the project.

According to Conole et al. (2006: 156), many students lack enthusiasm in using the virtual learning environment (VLE) because in most instances it serves as repositories for materials rather than being used in imaginative ways that will support learning. Hence, it is important to identify the learning management system where the project will take place.

Communication Tools. Interaction is done through the use of relevant online communication tools. Beetham et al. (2007) point out that some tutors are still insufficiently incompetent in using digital technologies for learning. According to Laurillard (2002), "interactivity in any teaching and learning context involves students responding to information, seeking feedback on their responses, reflecting on the feedback and acting appropriately to tailor their personal learning experiences.”

Monitoring and Evaluation. Monitoring is an on-going process during the project implementation stage. On the other hand, evaluation occurs periodically, typically when the project has been completed. Compared to monitoring, it has a broader perspective as it challenges the original assumption of the project design. It focuses on the project's progress towards realizing its purpose and goal.

\section{Methodology}

This paper presents the personal experiences of the author in managing tutoring and learning communities. Specifically, it will discuss how an e-learning project is planned, implemented, 
monitored and evaluated. Moreover, it will discuss the factors that contribute to the success of tutoring and learning communities; and draw lessons from the good practices.

\section{Managing Tutors and Learners Without Borders: Some Experiences and Lessons}

\section{Project Description}

In 2009, InWEnt, Capacity Building International, Germany, and the University of the Philippines Open University (UPOU) signed a Memorandum of Understanding to contribute to enhance e-learning worldwide, especially in Southeast Asia and the Philippines. Both organizations agreed to promote further development of e-skills training programs and elearning technologies in order to build a people-centered, inclusive and development-oriented Information Society.

\section{Goal of the Project}

The main goal of the project is to implement two e-learning programs, namely the eLearning Development and Implementation Asia (eLDI) program and e-skills courses.

The eLearning Development and Implementation (eLDI) Program. The eLDI Asia is an eight-month blended course consisting of six modules: Instructional Design, Content Development, Interactivity, eLearning Technology, eLearning Management and Tutoring for eLearning communities. The course involves about 50 hours of face-to-face workshops and 200 hours online.

The participants are entitled to a certificate after completing the course. They also have the option to take an exam conducted by the University of Furtwangen, Germany. If they pass the written examination, and their eLearning projects are assessed satisfactorily, then they are entitled to get credit units. Moreover, they are also given a certificate of expertise on "New Learning Technologies.

The eLearning-skills Courses (e-skills). The e-skills courses are conducted entirely online. They have six modules, which are similar with the eLDI modules except for Interactivity that is replaced by eLearning Strategy. A certificate is also issued for each module to participants who complete the course successfully.

Financial Support . The eLearning courses are funded by InWEnt. However, other institutions are willing to support their participants by paying the airfare to attend the face-toface workshops and the corresponding course fee. The course fees augment the budget of the program.

The Participants. The eLDI program aims to train 20-30 participants from developing countries in Asia, namely Cambodia, India, Indonesia, Mongolia, Nepal, the Philippines and Vietnam. Most participants are into capacity building or are involved in the use of ICT for learning.

The e-skills courses participants not only come from Asia but also from the Middle East. In some cases where there is an urgent need to include participants from Africa, InWEnt endorses the applicants. 
Unlike in the eLDI program, where the same people take part throughout the course, the eskills modules are offered separately. Hence, participants have the option to enroll in courses they are interested in or to take all the six courses.

Announcements and application forms for the course are distributed to all members of the learning community in the various Asian countries to enroll participants. These are also posted in the Global Campus 21 site of InWEnt and the UPOU website.

The Tutors. The participants are tutored by experts from Asia. Most of them have completed the eLDI or the e-skills courses themselves. They are selected based on their knowledge of the content, communication skills and their familiarity with eLearning. They normally start as assistant tutors where they learn to tutor and manage their courses. They are coached by a main tutor and by umbrella tutors on the use of communication tools and how to provide feedback on the tasks of participants.

Handbook of Tutors. This contains all the necessary information of the course such as the dates, the tutors and contacts. It also specifies the duties and responsibilities of tutors and assistant tutors, including how to track the progress of the participants.

\section{Program Content and Support}

Table 1 shows the contents of the project, including how the participants will be supported. For the eLDI, there are two face-to-face workshops, while the e-skills courses are completely offered online.

\section{Table 1. Program Content and Support} eLDI and e-skills

\begin{tabular}{|l|l|l|l|}
\hline \multicolumn{1}{|c|}{ Modules/Phases } & \multicolumn{1}{|c|}{$\begin{array}{c}\text { eLDI } \\
\text { Schedule }\end{array}$} & \multicolumn{1}{|c|}{$\begin{array}{c}\text { e-skills } \\
\text { Schedule }\end{array}$} & \multicolumn{1}{|c|}{ Support } \\
\hline & & & Finance Officer \\
\hline WS I - Face to Face & 1 week & None & Facilitators \\
\hline Online phase & & & Umbrella Tutors (eLDI) \\
\hline $\begin{array}{l}\text { eLearning Strategy } \\
\text { ID Instructional } \\
\text { Design }\end{array}$ & 4 weeks & 4 weeks & Toolbox Support \\
\hline $\begin{array}{l}\text { CD Content } \\
\text { Development }\end{array}$ & 4 weeks & 4 weeks & Tutors \\
\hline INT Interactivity & 4 weeks & None & Tutors \\
\hline $\begin{array}{l}\text { eLT eLearning } \\
\text { Technology }\end{array}$ & 4 weeks & 4 weeks & Tutors \\
\hline eLM eLearning & 4 weeks & 4 weeks & Tutors \\
\hline
\end{tabular}




\begin{tabular}{|c|c|c|c|}
\hline Management & & & \\
\hline $\begin{array}{l}\text { TeL Tutoring for } \\
\text { eLearning } \\
\text { Communities }\end{array}$ & 4 weeks & 4 weeks & Tutors \\
\hline WS II - Face to Face & 1 week & None & Facilitators \\
\hline
\end{tabular}

Learning Management System and Technologies. The eLDI and e-skills online phases are conducted through the use of Global Campus 21, a learning management system created for InWEnt. The course sites are created by the tech support and the modules are uploaded based on their schedule. The interactive elements, such as chats and discussion forum links, are also created to enable the participants to communicate with each other.

In addition, the UPOU also gives support by making its "MyPortal” LMS available to the eLDI participants for their e-Learning projects. The program also supports the use of free and open source software (FOSS) tools.

It should be noted that the tutors have their own site, called the Tutors' Lounge, where coaching and interaction takes place. Tutors also upload their own reports and chat on this site.

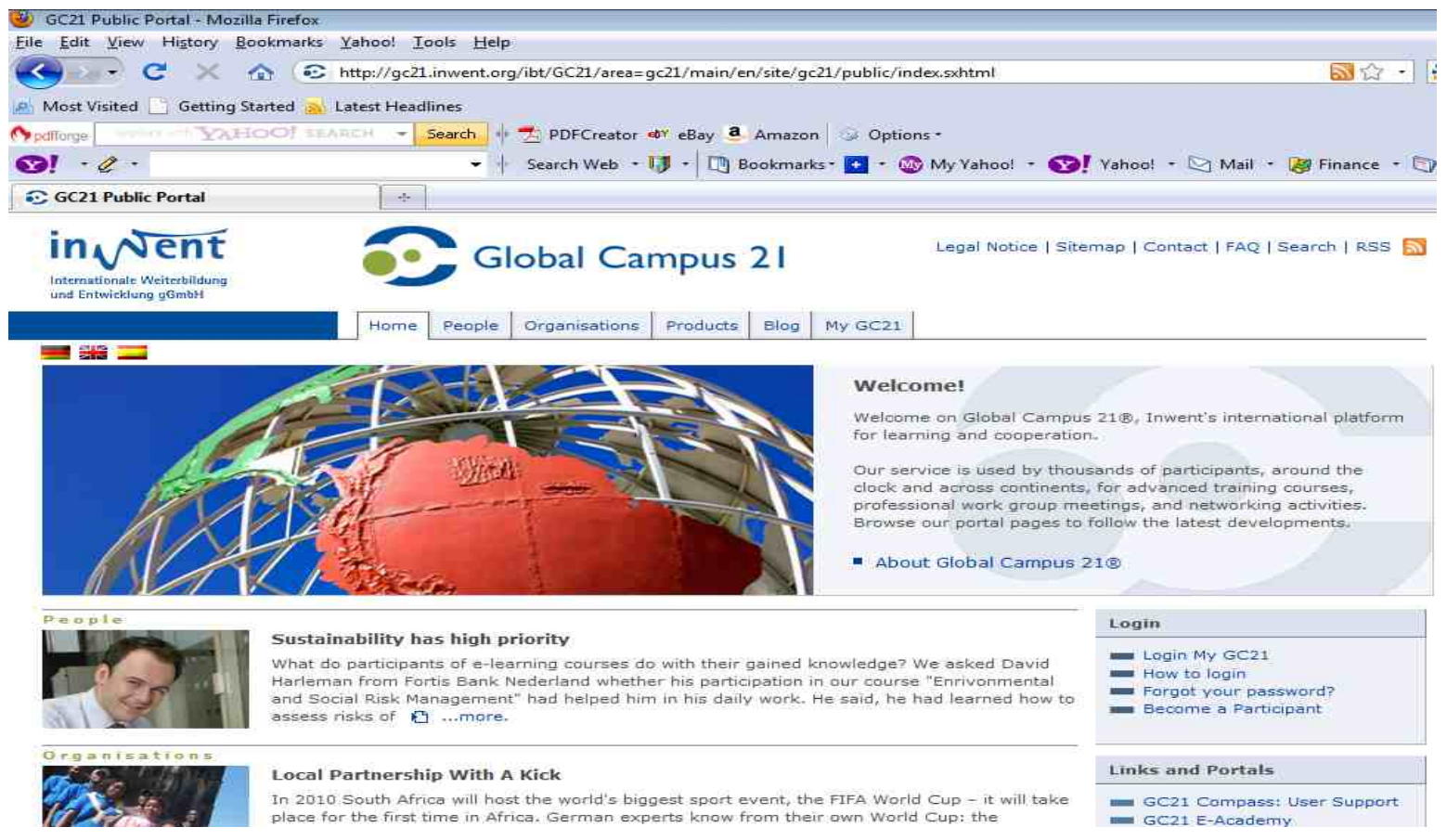

Figure 2: Global Campus 21 Portal

Communication Tools. The tutors and learners use various communication tools in these courses. They use email, chat and forums, which are helpful in formal and informal interaction. The Forum provides a venue to exchange information and knowledge which is moderated by the tutors and the learners. Through the forums, the tutors and participants can interact with each other. Chats are scheduled at least three times in each module. Emails provide fast and efficient communication between tutors, learners and the course manager. 

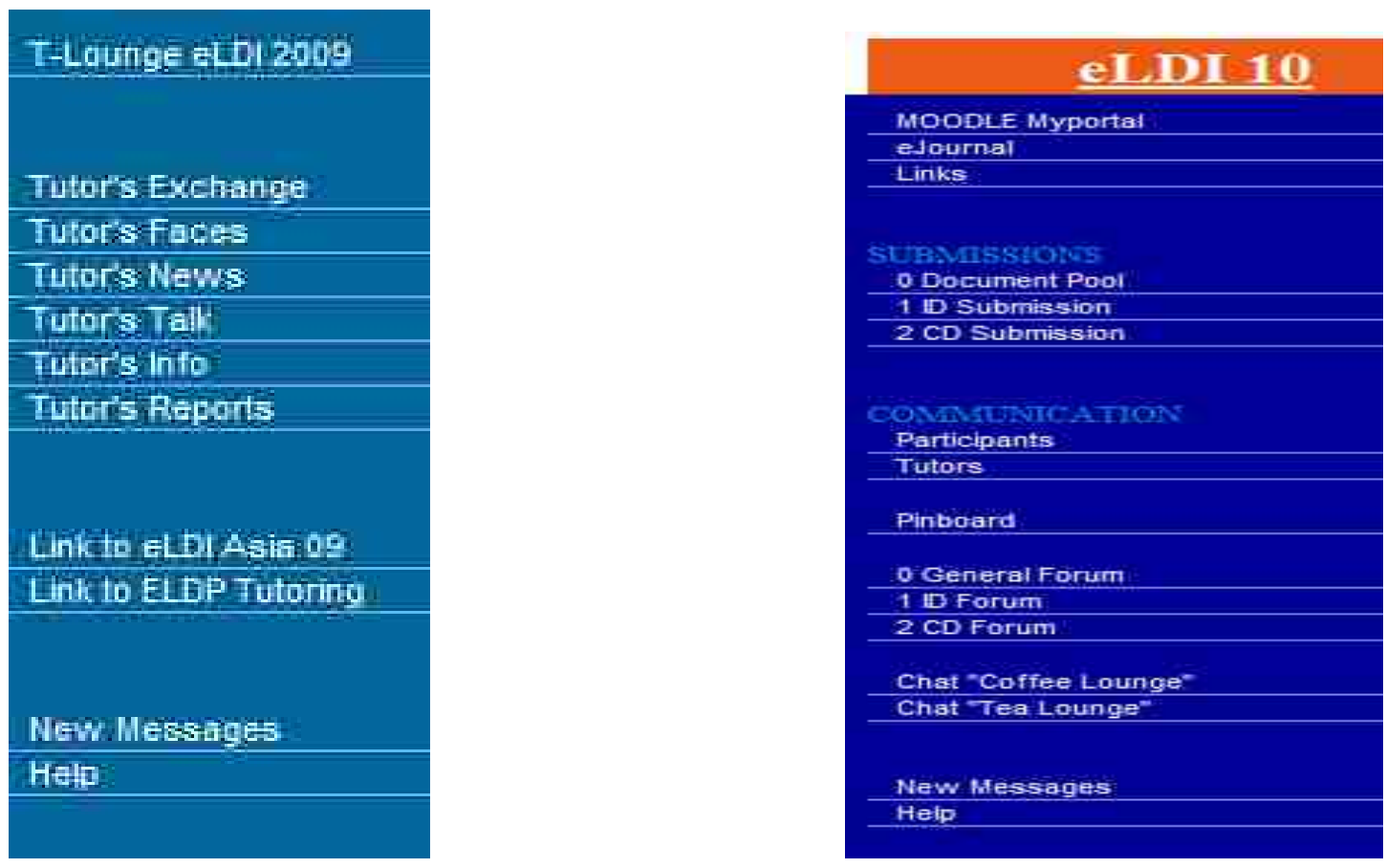

Figure 3: Communication Tools of Tutors and Participants

Monitoring and Evaluation. In order to monitor the performance of the learning community, a participant's track was designed for tutors to fill in the information on the activities of participants.

The tutors are required to submit a tutors' log which documents all their tutorial activities.

\section{Conclusion and Lessons Learned}

Managing global tutoring and learning communities can be a challenge but the goals can be achieved successfully if managed properly. From planning, implementation, monitoring to evaluation, certain factors contribute to the success of any virtual community.

The goals of tutoring and e-learning communities or any virtual community must be clear to all its members. Hence, their roles should be defined as well. This is also one way of establishing trust between one another.

Since interaction takes place through the Internet, the connection of these communities must be assured. Whatever tool is used for interaction, it is important that the members know how to use it.

The content must also be relevant to all members of the community. What is to be shared by the members should be determined earlier, in order to maintain and sustain the community.

Effective communication tools must also be used and supported by the technology being utilized by the members of the communities. The language must be simple enough for everyone to comprehend. With members of the community coming from various cultural backgrounds, certain rules must be clearly observed in communication. 
AAOU Journal, Vol. 6, No. 1, September 2011, 24-31

\section{References:}

Beetham, H. \& Sharpe, R. (2007). Rethinking pedagogy for a digital age: Designing and delivering e-learning. London \& New York: Routledge.

Conole, G., Laat, M. d., Dillon T., \& Darby, J. (2006). An in-depth case study of students' experiences of elearning - how is learning changing? Paper presented at the $23^{\text {rd }}$ Annual ASCILITE Conference: Who's Learning? Who's Technology?, Sydney, Australia.

Laurillard, D. (2002). Rethinking Teaching for the Knowledge Society. Reprinted with permission of the author and EDUCAUSE from EDUCAUSE Review, 37(1), 16-25. 